\title{
CUBA Y EUROPA: DIEZ AÑOS DE ENCUENTROS Y DESENCUENTROS
}

\section{Susanne Gratius}

Con motivo del primer centenario de su independencia como colonia española, Cuba parece estar recuperando sus raíces europeas: prueba de ello es el creciente papel de la Iglesia Católica en la isla, la reconciliación con España y el paulatino acercamiento a la Unión Europea (UE). Cabe recordar que 1998 es una importante fecha conmemorativa en las relaciones europeo-cubanas: la isla celebra no sólo los primeros cien años de su independencia de España, sino también se cumplen diez años de contactos diplomáticas con la UE. En este decenio, Europa ha ascendido, casi de forma involuntaria, de una posición marginal durante la Guerra Fría a ser el principal socio de Cuba, en términos de cooperación, comercio e inversiones.

Es probable que exactamente una década después de haberse restablecido las relaciones diplomáticas entre ambas partes, en septiembre de 1998, Cuba participe como observador en las negociaciones sobre la reforma del Convenio de Lomé entre la UE y los 71 países del Grupo de países de Africa, el Caribe y el Pacífico (ACP) ${ }^{1}$, que concluirán en el próximo milenio. Esto significaría el fin del período de estancamiento actual de las relaciones, desde que la UE aprobó en diciembre de 1996 la Posición Común sobre Cuba. Sin embargo, este nuevo rumbo en las relaciones europeo-cubanas no es una excepción, sino refleja una tendencia general de reinsertar a la isla en la comunidad internacional y distanciarse de la cada vez más aislada posición de Estados Unidos (EE UU).

Por ser uno de los pocos países socialistas que han sobrevivido a la caída del muro de Berlín, Cuba, que fue durante muchos años el enfant terrible de las relaciones internacionales, es ahora el invitado especial en numerosos foros multilaterales, convirtiéndose en el tema estrella al margen de la agenda oficial ${ }^{2}$. La creciente revalorización de Cuba en la comunidad internacional es en gran parte el resultado de una verdadera "ofensiva diplomática" del régimen cubano, que por primera vez en su historia reciente está buscando diversificar sus relaciones con el mundo, mientras que tradicionalmente dependía de un sólo aliado principal: primero EE UU y después de la Revolución la ex-Unión Soviética.

Por otra parte, el fin del aislamiento internacional de Cuba se debe también a los efectos positivos de la reciente visita del Papa Juan Pablo II, que parece haber fomentado una reconciliación de las posiciones en la isla y frente al exterior. Tras dos años de intromisión como consecuencia de la "crisis de las avionetas" en febrero de 1996 -cuando la Fuerza Aérea derrumbó a dos avionetas procedentes de EE UU-, el viaje del Papa a Cuba ha abierto un nuevo camino para una plena inserción del país en la comunidad internacional. Pocos meses después de su histórica visita, a finales de enero de 1998, parece cumplirse su deseo de que "Cuba se abra al mundo y el mundo se abra a Cuba". Las señales para ello son múltiples: el Gobierno de Fidel Castro liberalizó a unos cien presos políticos, EE UU levantó algunas restricciones contra la isla, Canadá se perfila como principal aliado del régimen en el hemisferio, España normalizó las relaciones con la isla y EE UU perdió por primera vez en siete años la votación contra Cuba en la Comisión de Derechos Humanos de las Naciones Unidas ${ }^{3}$.

¿Qué papel ha asumido Europa en este proceso de apertura? Aunque la UE se ha convertido en el principal socio económico de la isla, no es un actor político clave en el tema cubano. Después de las visitas a Cuba del Papa y del Primer Ministro canadiense, Jean Chrétien (en abril de 1998), todo indica que el Vaticano y Canadá están asumiendo un papel de mediación, tanto respecto a la situación interna en la isla, como en el conflicto bilateral CubaEE UU. Como principal fuente de cooperación, primer inversor y socio comercial, Europa es sobre todo la baza económica de Cuba, que sustituye gran parte de las relaciones preferenciales con el ex bloque socialista y garantiza la supervivencia de la isla. Esta tendencia se reforzaría aún más en el caso de una futura adhesión del país al nuevo Convenio de Lomé, a partir de marzo del año 2000. Sin embargo, la adhesión de Cuba a este Convenio está condicionada a una "cláusula democrática", que hasta ahora ha impedido formalizar las relaciones entre ambas partes.

Politóloga, Coordinadora de Proyectos en el Instituto de Relaciones Europeo-Latinoamericanas (IRELA) en Madrid.

1. Esto se ha podido observar en la reciente reunión, en mayo de 1998, de la Organización Mundial de Salud, así como en la II Cumbre de las Américas en Santiago de Chile (pese a que Cuba no participó).

2. Véase IRELA, "El mundo se abre a Cuba: avances hacia su plena inserción internacional”, Briefing n 3 , Madrid 1998.

3. La dimensión bilateral de las relaciones -Alemania, España, Francia y el Reino Unido- ha sido analizada por Wolf Grabendorff en su articulo "The Relationship between the European Union and Cuba", en: Tulchin, Joseph, Serbin, Andrés y Hernández, Rafael, (1997), op.cit. 


\section{ALTIBAJOS Y CONDICIONAMIENTOS DE LAS RELACIONES EUROPEO-CUBANAS}

Aunque los símbolos de la Revolución cubana -el antiimperialismo y el culto en torno al "Che" Guevarasiempre han despertado interés en Europa, durante la Guerra Fría no existía una política consensuada de la entonces Comunidad Europea, y las relaciones con Cuba se desarrollaron casi exclusivamente a nivel bilateral, sobre todo con España, Francia y la ex República Democrática Alemana ${ }^{4}$. Desde el restablecimiento de los contactos diplomáticos entre la UE y Cuba, las relaciones entre ambas partes se han caracterizado por continuos altibajos, alternándose breves períodos de "luna de miel" con momentos de crisis, casi siempre provocados por incidentes externos ${ }^{5}$. En la actualidad, a raíz de la visita del Papa y una cierta distensión del clima interno en Cuba, sus relaciones con la UE parecen estar transitando de una prolongada crisis hacia una nueva "luna de miel".

Esta permanente inestabilidad de las relaciones se debe a la influencia de factores ajenos a la propia dinámica de las relaciones europeo-cubanas, que siempre han estado condicionadas por los cambios en la política internacional y el diferendo entre Cuba y EE UU. Tradicionalmente, los lazos entre Europa y la isla se han insertado en el marco de tres ejes: en el triángulo atlántico-América Latina, la UE y EE UU-, el conflicto Este-Oeste y el diferendo Norte-Sur. Como punto de enlace entre las relaciones Norte-Sur y Este-Oeste, Cuba siempre ha tenido un estatus particular en la política de la UE. Durante la Guerra Fría, la pertenencia a bloques ideológicos distintos ha impedido una intensificación de las relaciones entre la UE y Cuba. Hasta el derrumbe del bloque socialista, la entonces Comunidad Europea no percibió a Cuba como país latinoamericano, sino como miembro del bloque socialista integrado en el Consejo de Ayuda Mutua Económica (CAME). Cuando la UE estableció en septiembre de 1988 relaciones diplomáticas con el bloque socialista, lo hizo también con Cuba, y fue a partir de este momento cuando el país comenzó a formar parte de la política latinoamericana de la UE. Sin embargo, hasta la actualidad es considerado como un "caso aparte” y sigue siendo el único país latinoamericano que no ha firmado un acuerdo de cooperación con la UE.

A diferencia de su intervención como mediador en la crisis centroamericana de los años ochenta, la UE no ha diseñado una política propia, coherente e independiente hacia Cuba ${ }^{6}$. Ello se debe, en primer lugar, a las considerables diferencias entre y en los Estados miembros -cabe recordar la polémica que desata el tema cubano en España-, que han impedido un consenso sobre una línea política común. En segundo lugar, está relacionado con el temor de enfrentarse a EE UU, que considera Cuba como un tema de política interna y ha convertido la derrota de Fidel Castro en su propia "causa justa". Una tercera razón para ello la constituyen los conflictos de intereses entre Cuba y algunos países de la Unión -sobre todo Francia- en África, que han creado cierto recelo histórico entre ambas partes. Aún así, se pueden identificar cuatro elementos constantes en la estrategia de la UE hacia Cuba:
- el rechazo de la política de sanciones de EE UU, incluyendo la Ley Helms-Burton,

- el mantenimiento de la cooperación con énfasis en la ayuda humanitaria ${ }^{7}$,

- el apoyo a las reformas económicas y una transición pacífica en la isla,

- un diálogo crítico-constructivo con las autoridades cubanas.

En los diez años transcurridos desde el restablecimiento de relaciones diplomáticas entre Cuba y la entonces Comunidad Europea, pueden distinguirse varias etapas que reflejan los continuos encuentros y desencuentros en las relaciones y su dependencia de los cambios en la escena internacional y la situación interna en la isla. Asimismo, la trayectoria de las relaciones señala que siempre han prevalecido los lazos económicos, mientras que los contactos políticos han sido mínimos -las Conferencias Interparlamentarias son el único foro birregional permanente en el que participa Cuba-, salvo en los pocos momentos de acercamiento de intereses. Es por ello que en estos diez años de diálogo, la UE y Cuba no han logrado formalizar sus relaciones mediante un acuerdo de cooperación, lo cual no ha impedido estrechar los lazos económicos entre ambas partes.

\section{Balance de las relaciones: alternancia entre acercamiento y distanciamiento}

Teniendo en cuenta que Cuba nunca ha sido un tema prioritario en la política de la UE, y que la isla tampoco ha diseñado una estrategia constante hacia Europa, sino que ha dado prioridad a los lazos bilaterales ${ }^{8}$, después del derumbe del campo socialista la UE se ha convertido casi de forma involuntaria en el principal socio económico y fuente de cooperación de Cuba. Esta posición privilegiada contrasta con un bajo perfil político, debido a diferentes percepciones en la cuestión de la democracia y los derechos humanos, la influencia de EE UU y varios incidentes que han impedido una plena normalización de las relaciones políticas. Siguiendo estos factores, desde el fin de la Guerra Fría, las relaciones se han caracterizado por la continua alternancia entre fases de acercamiento y distanciamiento, que permiten distinguir cuatro momentos claves en las relaciones:

4. Eduardo Pereira analiza los altibajos de las relaciones desde una perspectiva cubana en varios artículos, entre ellos "La UE y Cuba: hacia un mayor realismo en las relaciones", en: Revista de Estudios Europeos, Vol. 8, n³ 31, La Habana 1994.

5. En este sentido, el Canciller cubano, Roberto Robaina, afirma que las relaciones con Cuba constituyen un reto para la UE y su "legítima aspiración de diseñar una política exterior y de seguridad común independiente...", véase Roberto Robaina (1997), op.cit., p. 92.

6. Aunque los recursos concedidos a Cuba son escasos, la UE es el principal cooperante de la isla, al concentrar más del $80 \%$ del total recibido por el país. Entre 1992 y 1996, la UE y sus Estados miembros desembolsaron a Cuba un total de 163 millones de dólares

7. Véase Wolf Grabendorff, "The Relationship between the European Union and Cuba...” (1997), op. cit., p. 208.

8. El intercambio comercial entre ambas partes siempre ha sido limitado, porque Cuba y Europa son competidores en el sector azucarero, ya que la UE se ha perfilado desde finales de los años ochenta como principal exportador mundial de azúcar. 
1988-1990: Se inicia una primera fase de "acercamiento y reconocimiento mutuo". Tras décadas de relativa ignorancia recíproca, en este período, las relaciones experimentan un primer auge debido al restablecimiento de relaciones diplomáticas entre la UE y el CAME, y a iniciativa cubana, se vislumbra por primera vez la posibilidad de suscribir un acuerdo bilateral de cooperación. En esta fase de acercamiento se realizan varias visitas mutuas, entre ellas la de una delegación del Parlamento Europeo que viaja a La Habana para entrevistarse con las autoridades cubanas. Sin embargo, las conversaciones tentativas sobre un acuerdo de cooperación no avanzan, debido a diferencias políticas entre ambas partes y la cuestión del acceso al mercado europeo, sobre todo para el azúcar cubano, su principal producto de exportación ${ }^{9}$.

1990-1993: La “crisis de las Embajadas" en verano de 1990 produce un repentino estancamiento del diálogo y da lugar al primer conflicto diplomático en las relaciones europeo-cubanas desde el fin de la Guerra Fría. Como consecuencia de la caída del muro y el derrumbe del bloque socialista, centenares de cubanos se refugian en las Embajadas extranjeras en La Habana, principalmente de origen europeo. Después de casi dos meses, la crisis entre Cuba y los países europeos -entre ellos también algunos del ex bloque socialista- concluye mediante un acuerdo con el Gobierno de Castro y la concesión de asilo político para la mayoría de los refugiados. Aunque la situación se normaliza posteriormente, las relaciones políticas han sufrido un primer percance y siguen estancadas hasta 1995. El bajo perfil político de las relaciones marca un claro contraste con los crecientes intereses económicos de la UE en Cuba ${ }^{10}$, que se refleja en el auge del comercio bilateral, la creación de empresas mixtas con capital europeo y un aumento de la inversión directa desde la UE.

1993-1995: Se inicia un acercamiento mutuo sin precedentes: la UE y sus Estados miembros participan activamente en el proceso de reformas y transformaciones económicas en Cuba. La Comisión Europea aumenta sus compromisos de ayuda para Cuba de 4,2 millones de ECUs en 1992 a 30 millones en 1995 y concede por primera vez cooperación económica. Asimismo, empresas europeas -sobre todo españolas- se convierten en los principales inversores extranjeros en la isla y co-financian cerca de un tercio de las empresas mixtas. Este auge de las relaciones económicas se traduce también en un mayor acercamiento a nivel político. A iniciativa de España, que ostenta la Presidencia de la UE en el segundo semestre de 1995 , se identifica por segunda vez la posibilidad de negociar un acuerdo bilateral de cooperación con Cuba. A raíz de un viaje previo de la Troika de la UE a La Habana, el Consejo Europeo de Madrid aprueba en diciembre de 1995 el mandato de negociación para definir un acuerdo con Cuba.

1996-1997: La "crisis de las avionetas" del 24 de febrero de 1996 pone fin al breve período de acercamiento. La entrevista que sostiene el Vicepresidente de la Comisión Europea, Manuel Marín, pocos días antes del incidente con el Gobierno cubano disminuye las perspectivas de firmar un acuerdo de cooperación. Las diferencias políticas -en términos de derechos humanos y sistema político- parecen irresolubles, ya que Cuba insiste en su soberanía política y la Comisión Europea en la cláusula democrática, que condiciona casi todos sus acuerdos de cooperación. Diez días después de la visita de Marín a la isla, el 24 de febrero de 1996, la Fuerza Aérea cubana derriba a dos avionetas civiles procedentes de EE UU -que habían violado el espacio aéreo cubano- y causa la muerte de sus cuatro tripulantes. EE UU reacciona con la aprobación de la Ley HelmsBurton en su versión más dura. Con el argumento de cerrar las filas frente al enemigo externo, EE UU, se endurece la situación interna en Cuba, se detienen nuevos disidentes, se frena el proceso de reformas económicas y un Informe del Buró Político presentado por Raúl Castro lanza una seria advertencia a todos los sectores que se desvíen de la línea oficial del Partido Comunista de Cuba ${ }^{11}$.

La UE condena la actuación cubana, decide congelar el acuerdo de cooperación y se distancia del régimen de Fidel Castro, lo cual produce un mayor consenso con EE UU. El cambio de Gobierno en España, de Felipe González a José María Aznar, y la crisis diplomática entre ambos países contribuye a un cierto endurecimiento de la política de la UE hacia Cuba con la aprobación de la Posición Común a finales del año, que condiciona por primera vez un acuerdo bilateral y la cooperación a avances visibles hacia la democracia y el respeto de los derechos humanos en la isla. Asimismo, la Posición Común abre el camino hacia un acuerdo con EE UU sobre la Ley Helms-Burton.

\section{Los condicionantes internos y externos de las relaciones ${ }^{12}$}

Esta última crisis reveló que las relaciones entre la UE y Cuba dependen de una serie de factores externos e internos. En primer lugar, la dinámica propia de las relaciones europeo-cubanas ha estado muy condicionada al diferendo entre Cuba y EE UU y su política de sanciones. Aunque la UE se opone al embargo y la estrategia de aislamiento de Washington, su política hacia Cuba siempre ha tenido en cuenta la posición de EE UU. Así, en momentos de relativa distensión entre ambos países -en 1995 cuando se produjo un breve acercamiento-, la UE ha fortalecido sus contactos con la isla, y en momentos de enfrentamiento -durante la "crisis de las avionetas"- se produjo un mayor distanciamiento. Ello se ha revelado en el caso de la Posición Común sobre Cuba, que fue aprobada en diciembre de 1996 en el contexto de la Ley Helms-Burton y supuso en cierto modo una "concesión" a los intereses de EE

9. Tras el derrumbe del bloque socialista, Cuba inicia un proceso de reformas económicas, que incluye una nueva y más liberal Ley de Inversiones, la apertura de zonas francas, la libre tenencia del dólar, la autorización del "trabajo por cuenta propia" y la apertura parcial del libre mercado agrícola y artesanal.

10. Véase el Informe de IRELA., "Cuba y la Unión Europea: las dificultades del diálogo", Briefing n ${ }^{\circ}$ 5, Madrid 1996.

11. Para un análisis detallado de los condicionamientos de las relaciones europeo-cubanas desde la perspectiva cubana, véase Eduardo Perera Gómez, "Cuba y la UE: los factores del estancamiento", en: Revista de Estudios Europeos, n ${ }^{\circ}$ 40, La Habana, 1996, pp. 78-116.

12. El Gobierno de EE UU levantó el 20 de marzo de 1998 tres sanciones contra Cuba: se restablece la ayuda humanitaria y los vuelos directos con fines humanitarios, se autoriza el envío de 1.200 dólares anuales en remesas familiares y se facilitan los trámites para enviar medicinas a la isla. 
UU y el deseo de llegar a un compromiso con el principal socio de la UE ${ }^{13}$. Esta misma tendencia se percibe también en el actual debate sobre la posible adhesión de Cuba al Convenio de Lomé UE-ACP, que se enmarca en una cierta distensión de las relaciones EE UU-Cuba y un clima internacional favorable, caracterizado por una apertura recíproca entre Cuba y el mundo y el levantamiento de algunas sanciones por parte de EE UU ${ }^{14}$.

Por otra parte, la trayectoria de las relaciones señaló que el tema de la democracia y los derechos humanos es el punto álgido en las relaciones europeo-cubanas, que ha impedido durante diez años la normalización de la cooperación, en abierta contradicción con los crecientes lazos económicos. Parece que el régimen de Fidel Castro calcula los costes de un acuerdo de cooperación con la UE más altos que sus beneficios -teniendo en cuenta que también sin acuerdo existen relaciones económicas y de cooperación-, ya que no está dispuesto hacer concesiones en materia de democracia y derechos humanos y aceptar la cláusula democrática que exige la UE. Esta resistencia por parte de las autoridades cubanas contrasta con el hecho de que el país mantiene desde 1997 un diálogo sobre democracia y derechos humanos con Canadá y firma cada año las declaraciones políticas de las Cumbres Iberoamericanas. Desde la perspectiva del régimen cubano, la UE condiciona el diálogo y un acuerdo de cooperación a cambios en el sistema político, lo cual considera inaceptable y discriminatorio ${ }^{15}$. La UE, en cambio, opina que aplica a Cuba las mismas reglas que a sus demás socios, siguiendo las líneas de cooperación al desarrollo establecidas en el Tratado de Maastricht y la inclusión de una cláusula democrática en prácticamente todos sus acuerdos con países terceros. No obstante, cabe recordar que en el caso de Cuba, esta política tradicional ha sido reforzada por la Posición Común, según la cual una plena cooperación dependerá del pleno respeto de los derechos humanos" y "avances hacia la democracia".

Otro importante condicionante son las relaciones entre España y Cuba. Como tradicional interlocutor europeo de la isla, España ha tenido un papel clave en el debate sobre la Posición Común y la definición de la política de la UE hacia la isla. En este sentido, ha sido uno de los principales responsables de los drásticos cambios en las relaciones en los últimos años. Mientras que Felipe González impulsó en 1995 un sustancial acercamiento entre ambas partes, el actual Gobierno de Aznar pugnó por la aprobación de la Posición Común sobre Cuba y contribuyó sustancialmente a un cierto endurecimiento de la política europea y un mayor consenso con EE UU. En este contexto, es interesante observar que en el marco del actual debate sobre la posible inclusión de Cuba en el Convenio de Lomé, España podría perder su tradicional papel frente a Cuba, ya que Francia y el Reino Unido asumen una posición mucho más importante en las negociaciones sobre la reforma de Lomé.

\section{EL DEBATE SOBRE LA LEY HELMS-BURTON}

El conflicto sobre la Ley Helms-Burton y su reciente desenlace es el mejor ejemplo para ilustrar el condicionamiento de las relaciones europeo-cubanas a la posición de
EE UU. Más que una política de sanción extraterritorial, la Ley Helms-Burton ha representado una amenaza eficaz para desincentivar la inversión extranjera en Cuba y conseguir un mayor consenso entre EE UU y sus aliados con respecto al rechazo del régimen cubano por diferencias políticas. Aunque sus disposiciones extraterritoriales apenas han sido llevadas a la práctica (en parte por su incompatibilidad con el Derecho Internacional), sigue siendo una espada de Damocles para los que están haciendo negocios en Cuba. Conscientes de las dificultades jurídicas para aplicar esta Ley -cuyos artículos III y IV penalizan a compañías que invierten en ex propiedades estadounidenses nacionalizadas por la Revolución- la Administración Clinton la utilizó para presionar durante dos años a Canadá, América Latina y Europa para que sigan su política de aislamiento contra Cuba. Asimismo, fue una estrategia para llegar a un acuerdo con los países europeos, que permita declarar ilegal y discriminatoria la expropiación de bienes de EE UU por el régimen cubano.

Esta estrategia ha sido, al menos parcialmente, exitosa: en parte como respuesta a la campaña internacional de $\mathrm{EE}$ UU de incrementar la presión hacia Cuba en favor de un cambio democrático, la UE aprobó en diciembre de 1996 la Posición Común, que condiciona por primera vez explícitamente la cooperación a cambios democráticos en Cuba y obliga a todos los Estados miembros a seguir esta línea. En este sentido, también cabe la sospecha de si fue una mera casualidad que unas semanas antes de aprobarse la Posición Común se creara en España la Fundación Hispano-Cubana -percibida por algunos como sucursal de la Fundación Nacional Cubano-Americana (FNCA) en Miami- y que unos días después, el entonces recién nombrado Embajador español en Cuba, José Coderch, hiciera público sus futuros vínculos con la disidencia interna en Cuba, lo cual desde el punto de vista del régimen fue motivo suficiente para retirarle en noviembre de 1996 el plácet.

No obstante, pese a un cierto acercamiento a los intereses de EE UU en el ámbito político, la UE rechazó los efectos extraterritoriales de la Ley Helms-Burton y lo manifestó a través de un reglamento antídoto y la presentación de una demanda ante la OMC, el 20 de noviembre de 1996. Posteriormente, esta firmeza inicial contra la Ley Helms-Burton fue perdiendo vigor y cedió a un paulatino acercamiento entre ambas partes mediante un proceso de negociación entre el Vicepresidente de la Comisión Europea, Leon Brittan, y el Subsecretario de Comercio de EE UU, Stuart Eizenstat. Ambas partes consensuaron el 11 de abril de 1997 un primer acuerdo preliminar y la UE retiró posteriormente su demanda ante la OMC. EE UU, por su parte, se comprometió a suspender durante la Administración Clinton la aplicación del título III de la Ley-que permite la presentación de demandas en EE UU

13. Roberto Robaina, op. cit., p. 93: "Cuba no acepta, ni va a aceptar nunca la condicionalidad y el trato discriminatorio para una cooperación ni para cualquier paso futuro en sus relaciones exteriores".

14. Véase el texto original del acuerdo (accesible en la página web del Gobierno británico en Internet), "Understanding with Repect to Disciplines for the Strengthening of Investment Protections”, 18 de mayo de 1998.

15. Granma, La Habana, 19 de mayo de 1998 
contra empresas que invierten en bienes expropiados en Cuba- y de conseguir en el Congreso una enmienda al título IV -que deniega a representantes de empresas que negocian con bienes expropiados en Cuba el visado de entrada a EE UU.

\section{El acuerdo de la Cumbre Transatlántica: una dudosa victoria para la UE}

Después de vencer el 20 de abril de 1998 el plazo de reanudar la demanda de la UE ante la OMC, ambas partes suscribieron durante la Cumbre Transatlántica de Londres un nuevo acuerdo sobre las Leyes Helms-Burton y d'Amato-Kennedy. Con este acuerdo, la Ley Helms-Burton ha perdido ímpetu, al menos para las empresas europeas que invierten en Cuba, y el debate se trasladará al Acuerdo Multilateral de Inversiones en la OCDE, ya que la UE y EE UU se comprometieron a presentar próximamente una propuesta común para establecer nuevas normas en el caso de inversiones en bienes expropiados. El acuerdo bilateral ${ }^{16}$ establece que el Gobierno de Clinton reconoce las inversiones europeas realizadas hasta el 18 de mayo de 1998 en Cuba y se compromete a conseguir del Congreso una suspensión ilimitada de las sanciones extraterritoriales en el caso de la UE. Con ello, la UE consiguió que la actual inversión europea en Cuba no sea penalizada en EE UU y que el Gobierno continúe las consultas con el Congreso sobre la suspensión ilimitada de los títulos III y IV para empresas europeas, lo cual ya había anunciado hace un año.

El precio para ello fue alto: a cambio, EE UU obtuvo el compromiso político de la UE de fortalecer las disciplinas contra la inversión en propiedades expropiadas, desincentivar futuras inversiones en Cuba e internacionalizar el acuerdo bilateral a través de su inclusión en el Acuerdo Multilateral de Inversiones (AMI). De este modo, la UE se comprometió a impedir, o al menos desincentivar, futuras inversiones de empresas europeas en Cuba. Según el texto del acuerdo, Europa sancionará inversiones en bienes expropiados de forma ilegal o discriminatoria -en alusión a Cuba-, a través de campañas públicas y la denegación de apoyo gubernamental mediante préstamos o seguros. Asimismo, conjuntamente, se establecerán y harán públicas listas de reclamaciones de bienes expropiados, que podrían incluir no sólo las 5.911 registradas en EE UU, sino también las que presentarán los cubano-americanos. El Consejo de la UE ratificó el acuerdo el 25 de mayo, aunque condicionó su plena aplicación al cumplimiento del compromiso asumido por EE UU. Asimismo, en una Declaración Unilateral adjunta, la UE reafirmó su oposición a sanciones extraterritoriales y reiteró que presentará una nueva querella ante la OMC si alguna empresa europea se viera afectada por las sanciones de la Ley Helms-Burton. Las reacciones en Europa fueron mayoritariamente positivias y la prensa europea llegó a interpretar el acuerdo como una “victoria para la UE" (El País del 19 de mayo). Las reacciones en Cuba fueron naturalmente contrarias: Fidel Castro calificó el acuerdo en su discurso ante la OMC, el 19 de mayo, como "contradictorio, confuso y amenazante" y sostuvo que "un acuerdo a expensas de Cuba sería un deshonor para la UE” ${ }^{17}$.
Aunque la UE ha conseguido la protección de la inversión actual en Cuba, de hecho ha aceptado la legalidad de las demandas de EE UU contra inversiones en bienes expropiados en Cuba considerados discriminatorios, a la vez que participará en la campaña de desincentivar inversiones en la isla. Aunque las consecuencias para Cuba serán mucho más dramáticas que para la UE, este acuerdo bilateral podría crear un peligroso antecedente en el Derecho Internacional y en el futuro de las relaciones comerciales transatlánticas. Con ello, la denuncia del régimen cubano, de que EE UU intenta internacionalizar la Ley Helms-Burton con la ayuda de la UE, no parece tan lejos de la verdad.

\section{LA RECONCILIACIÓN ENTRE CUBA Y ESPAÑA}

Como principal inversor y socio comercial de Cuba en la UE, España sería el principal afectado del nuevo acuerdo. No obstante, pese al creciente interés económico de España en Cuba, el acuerdo entre la UE y EE UU ha pasado prácticamente inadvertido y hasta ahora no ha habido ninguna reacción oficial por parte de la comunidad empresarial española. España es uno de los países que más se ha beneficiado de la apertura económica en Cuba: es su principal suministrador de bienes y mercado de exportación y segundo inversor después de Canadá. Asimismo, 70 de las 300 empresas mixtas creadas en Cuba cuentan con capital español y numerosos bancos, cadenas hoteleras e importantes compañías (Endesa, Tabacalera) se empiezan a situar en la mayor economía del Caribe. En este sentido, el viaje en abril de 1998 de una importante delegación empresarial española, encabezada por el Presidente de la Confederación Española de Organizaciones Empresariales (CEOE), José María Cuevas, consolidó el creciente interés de España en invertir y comerciar con Cuba.

Como principal socio económico, cultural y político europeo de Cuba, España ha ejercido desde 1986 una considerable influencia en la política de la UE hacia la isla. Hasta la toma de posesión del Gobierno de Aznar, que supuso una cierta ruptura con esta tradicional línea política, se pueden identificar tres elementos constantes en la posición española frente a Cuba. Desde el régimen autoritario hasta la actualidad, España se ha opuesto enérgicamente a la política de sanciones de EE UU, mantuvo las relaciones económicas y de cooperación con Cuba y estableció un diálogo político crítico-constructivo con el régimen de Fidel Castro. Asimismo, desde su inauguración en 1991 en Guadalajara (México), Cuba participa en las Cumbres Iberoamericanas de Naciones, que se celebran cada año en uno de los 19 países participantes y que tendrá

16. El diputado Guillermo Gortázar explica con detalle la nueva política española hacia Cuba. Para ello, véase su ponencia en FundACIÓN DiÁlogos, "Simposio internacional: una nueva política hacia Cuba", Madrid 1997, p. 43-59.

17. La propuesta inicial española preveía, entre otros, nombrar en cada embajada europea un encargado de las relaciones con la disidencia y el fortalecimiento de la presión al régimen cubano en foros internacionales para realizar avances hacia la democracia y el pleno respeto de los derechos humanos. Para el debate sobre la Posición Común, véase IRELA, "La Posición Común de la UE sobre Cuba: debate interno, reacciones y repercusiones", Briefing n 6, Madrid 1996. 
lugar en La Habana en 1999. Asimismo, a partir de 1998, Cuba ha vuelto a asistir con pleno derecho a las reuniones anuales del Parlamento Iberoamericano, que se ha celebrado este año en Montevideo.

\section{La "nueva" política española hacia Cuba}

Aunque las relaciones sufrieron varios altibajos en el pasado reciente ${ }^{18}$, la primera crisis diplomática de larga duración se produjo durante el Gobierno de José María Aznar, que había anunciado ya durante su campaña electoral un cambio en su política hacia Cuba. El conflicto diplomático entre ambos países se produjo el 25 de noviembre de 1996, cuando las autoridades cubanas retiraron el plácet al entonces recién nombrado Embajador José Coderch. Esta drástica medida fue la reacción a las declaraciones públicas de Coderch en favor de la apertura de un diálogo regular con la disidencia interna en la isla, calificadas por el Gobierno de Castro como "flagrante intromisión en los asuntos internos de Cuba". Aparte de este incidente, que fue más bien el detonante de una "crisis anunciada", la medida fue la respuesta al cambio de la política española ${ }^{19}$ hacia Cuba, que se reflejaba en los siguientes acontecimientos:

- El 25 de mayo de 1996, con ocasión de la visita a España del Vicepresidente de EE UU, Al Gore, el Gobierno de José María Aznar anunció la congelación de la ayuda hacia Cuba, excepto la humanitaria. Aunque ésta fue posteriormente restablecida, dicha decisión marcó el inicio de una nueva política más cercana a la posición de EE UU.

- Paralelamente, se intensificó el diálogo entre Gobierno y miembros de la comunidad del exilio cubano, entre otros con representantes de la conservador Fundación Nacional Cubano-Americana en Miami. A raíz de ello, se creó el 14 de noviembre de 1996 en Madrid la Fundación Hispano-Cubana, integrada por miembros del Partido Popular, académicos y representantes de la oposición cubana en el exilio, entre ellos el ya fallecido fundador de la FNCA, Jorge Mas Canosa.

- En este mismo día, España presentó a la UE su propuesta de adoptar una Posición Común sobre Cuba. Según algunas fuentes, el texto inicial proponía un mensaje mucho más firme con respecto a la democracia y los derechos humanos y estuvo más cercano a la política de EE UU que lo finalmente acordado.

El nuevo enfoque de la política española hacia Cuba y la decisión del Gobierno cubano de retirar el plácet al entonces Embajador, desataron un intenso debate interno en España, que marcó las líneas divisorias dentro y entre los partidos políticos. Asimismo, señaló que, al igual que en EE UU, por obvias razones históricas, el tema cubano no es sólo un tema de política exterior, sino que tiene repercusiones notables en la política interna española. La polémica nacional sobre la nueva política hacia Cuba, junto a la presión de la comunidad empresarial española, puede haber ejercido cierta influencia en la decisión del Gobierno de Aznar de rectificar el endurecimiento de su posición hacia Cuba. Tampoco puede descartarse una mediación de los Reyes de España, que durante varios meses señalaron un marcado interés en visitar la isla en el año conmemorativo 1998.

\section{La fase de rectificación}

Después de un año y medio de crisis diplomática, España nombró el 2 de abril de 1998 un nuevo embajador en Cuba, abriendo el camino hacia una plena normalización de las relaciones. Aparte de la presión interna, también la visita del Papa a Cuba y la posterior liberación de numerosos presos políticos han contribuido a la reconciliación entre ambos países, que conmemoran en 1998 los cien años de independencia de la ex colonia española. El nombramiento del nuevo embajador en Cuba, el diplomático Eduardo Junco Bonet, inaugura una nueva etapa en las relaciones, poniendo fin al "experimento" de incrementar la presión política al régimen cubano y acercarse a las posiciones del exilio. Todo indica que el Gobierno de Aznar volverá a adoptar la tradicional línea política española hacia Cuba: estrechas relaciones culturales y económicas, ayuda humanitaria y un diálogo político crítico.

Así, el reciente anuncio de la visita del Ministro de Asuntos Exteriores, Abel Matutes, a Cuba en verano de este año, así como el viaje de José María Aznar y de los Reyes de España en 1999, con motivo de la Cumbre Iberoamericana en La Habana, comprueban el deseo de normalizar las relaciones diplomáticas con Cuba. También del lado cubano existe un marcado interés en restablecer plenas relaciones con su principal socio europeo. Esto se reflejó en la visita relámpago del Canciller Roberto Robaina a Madrid tras el nombramiento del nuevo Embajador, ocasión en la cual se entrevistó también con el Presidente del Gobierno y el Rey Juan Carlos. También la entrevista sorpresa que Fidel Castro concedió a Eduardo Junco Bonet cuando éste presentó el 29 de abril sus credenciales en Cuba, demostró la buena voluntad del régimen de reconciliarse con España. Con estos últimos acontecimientos parece que se ha restablecido la situación anterior a la crisis, aunque es posible que con el experimento de cambiar la tradicional política hacia Cuba, otros países como Francia o Italia, hayan recuperado influencia en el tema cubano.

\section{LAS PERSPECTIVAS: ¿IINGRESARÁ CUBA EN EL CONVENIO DE LOMÉ?}

La normalización de las relaciones entre Cuba y España es una importante condición para poner fin al actual estancamiento de las relaciones europeo-cubanas. Mientras que el debate sobre un acuerdo bilateral de cooperación parece haber entrado en una vía muerta, Cuba ha propues-

18. Felipe Sahagún sostiene que "muchos españoles siguen viviendo la realidad cubana como si de un asunto interno se tratara y cualquier cambio en la política española hacia Cuba puede tener un efecto multiplicador [en la política de] la UE”. Felipe SAHAGÚN, op.cit., p. 6.

19. El Ministro de Cooperación francés, Charles Josselin, que visitó la isla el 3 y 4 de mayo de 1998, se pronunció a favor de la adhesión de Cuba al Convenio de Lomé. 
to continuar el debate en el marco multilateral de las relaciones entre la UE y los países ACP. El Canciller cubano solicitó en una carta oficial del 26 de febrero de 1998 la participación de Cuba en calidad de observador en las negociaciones sobre la reforma del Convenio de Lomé ACP-UE.

Cuba ya ha ganado la mitad de la partida, al haber obtenido el pleno respaldo político de los 71 países del ACP. Su Consejo de Ministros aprobó en la reunión, celebrada el 5 y 6 de mayo de 1998 en Barbados -en presencia de Cuba-, el ingreso del país como miembro observador en el grupo y se pronunció a favor de su participación en las negociaciones con la UE sobre el futuro de Lomé. Aparte de constituir una vía para formalizar las relaciones con la UE, la vinculación de Cuba al grupo ACP constituye un avance sustancial en su estrategia de diversificar las relaciones exteriores, a la vez que refleja un mayor reconocimiento de las raíces caribeñas y africanas de la isla.

El apoyo político de los países ACP le garantiza a Cuba una posición más favorable frente a la UE, que en el caso del congelado acuerdo bilateral. Aunque la UE todavía no ha tomado una decisión final sobre la participación de Cuba, ya que no existe un consenso entre todos los Estados miembros, las perspectivas para la vinculación de la isla a este Convenio parecen alentadoras. Varios actores europeos ya se han pronunciado a favor de la solicitud, entre ellos la Asamblea Paritaria UE-ACP -que reúne los parlamentarios de ambas partes-, Francia y España.

\section{Hacia una nueva dinámica en las relaciones}

La iniciativa ha introducido una nueva dinámica en las relaciones europeo-cubanas. En primer lugar, el debate sobre Cuba se traslada del nivel bilateral a un enfoque multilateral en el marco del diálogo entre la UE y los Estados ACP. Dado que este grupo de países aceptó la presencia de Cuba en las negociaciones sobre el futuro de Lomé, el Gobierno de Castro puede ejercer una mayor presión sobre la UE que en las negociaciones sobre un acuerdo bilateral de cooperación. Asimismo, es importante subrayar que este proceso conlleva un cambio de prioridades a nivel bilateral: si España fue el interlocutor clave en la cuestión de un posible acuerdo de cooperación UE-Cuba, Francia y también el Reino Unido tienen un papel más destacado en el Convenio de Lomé. Por otra parte, la posible adhesión de Cuba a este Convenio sería menos conflictiva que un acuerdo bilateral con la UE, que le concedería condiciones especiales y podría provocar mayores diferencias con EE UU.

En segundo lugar, dentro de la Comisión Europea, el tema cubano pasaría del Vicepresidente Manuel Marín -inamovible en el tema de los derechos humanos- a manos del Comisario de cooperación y relaciones con los países ACP, el portugués Joao de Deus Pinheiro. Aunque también el Convenio de Lomé contiene una cláusula democrática, podría haber una mayor flexibilidad, dado que la aplicación de la misma incluye a 71 países del grupo ACP, que no siempre siguen estrictamente el modelo democrático occidental. En este sentido, podría haber una mayor probabilidad de que ambas partes lleguen a un acuerdo sobre la cuestión del "condicionamiento político" que ha impedido hasta ahora la plena normalización de las relaciones europeo-cubanas.

En tercer lugar, la participación del país como observador en las negociaciones sobre el futuro del Convenio de Lomé implica una posible modificación de la Posición Común sobre Cuba, que hasta ahora fue ratificada dos veces y será revisada en junio de 1998 en el Consejo de Asuntos Generales de la UE. En el contexto actual, hay varios argumentos en favor de una revisión de la política de la UE hacia Cuba:

- La reciente liberalización de presos políticos en Cuba fue un gesto político favorable a una revisión de la política de la UE, ya que el régimen de Castro hizo un primer gesto hacia una mayor libertad en la isla. En su Declaración del 24 de febrero de 1998, la Presidencia de la UE acogió favorablemente la evolución interna en Cuba y expresó su deseo de que continúe esta tendencia e incluya la liberación de todos los presos políticos.

- El sustancial acercamiento entre la UE y EE UU en la cuestión de la Ley Helms-Burton. La Posición Común fue un paso decisivo para conseguir un compromiso entre ambas partes, ya que se adoptó también como respuesta a la campaña internacional de EE UU para promover la democracia y los derechos humanos en Cuba. En este sentido, el reciente acuerdo entre la UE y EE UU resta importancia a la Posición Común.

- La normalización de las relaciones entre Cuba y España con el nombramiento del nuevo embajador en la isla. La prolongada crisis diplomática se había iniciado poco antes de la aprobación de la Posición Común, y no cabe duda de que el conflicto bilateral reforzó el condicionamiento político de la cooperación con Cuba.

Si no se produce una nueva crisis en Cuba y continúa la tendencia de su paulatina inserción en las relaciones internacionales, existe, quizás por primera vez en diez años, la oportunidad de abrir un diálogo permanente y prolongado entre la UE y Cuba, que podría desembocar en su inclusión en el Convenio de Lomé. En 1998, las perspectivas para la plena inserción de Cuba en la política latinoamericana de la UE son nuevamente alentadoras, siempre y cuando no se produzca ningún incidente imprevisto. Así, se ha iniciado un diálogo sobre la vinculación de Cuba al proceso de Lomé y, a diferencia de las Cumbres de las Américas, el país ha sido invitado a participar en la I Cumbre Europeo-Latinoamericana, que se celebrará en 1999 en Rio de Janeiro. Si la UE decide favorablemente sobre la participación de Cuba en el proceso de negociaciones sobre Lomé, sería posible que el país se integre en el nuevo convenio, que entraría en vigor en marzo de 2000. No obstante, ello dependerá del interés de ambas partes en llegar a un acuerdo en el tan delicado asunto de la democracia y los derechos humanos.

La trayectoria de los últimos diez años señala que las relaciones entre la UE y Cuba se han caracterizado por una continua alternancia entre encuentros y desencuentros. En 
este sentido, cabe advertir que a las breves "luna de miel" siguió casi siempre una "luna de hiel". Esto se ha podido comprobar en 1989, cuando el acercamiento mutuo fue interrumpido por la "crisis de las Embajadas", y nuevamente en 1995, cuando las negociaciones sobre un acuerdo de cooperación fueron congeladas por la "crisis de las avionetas". En este sentido, es probable que las relaciones europeo-cubanas se sigan caracterizando por continuos altibajos, provocados por crisis externas y condicionadas por la situación interna en Cuba, que celebra el 1 de enero de 1999 los 40 años de Revolución.

\section{REFERENCIAS BIBLIOGRÁFICAS}

Alonso, José Antonio y DíAz VÁzQuez, Julio. (1996), "Presente y futuro de los intereses españoles en $\mathrm{Cu}$ ba”, Meridiano CERI, No 12, Madrid, pp- 17-20.

Encuentro de la Cultura Cubana. (1997), "Cuba a la luz de otras transiciones" (monográfico con varios autores), $\mathrm{N}^{\circ}$ 6/7, Madrid.

ERISMAN, Michael. (1998), "Cuba and the Caribbean Basin: From Pariah to Partner?", Journal of Interamerican Studies and World Affairs, Vol. 40, n 1, Coral Gable/ Florida, pp. 87-94.

FundACIÓN DiÁlOGOS. (1997), "Simposio internacional: una nueva política hacia Cuba", Madrid: Fundación Diálogos.

GRABENDORFF, Wolf. (1997), "The Relationship between the European Union and Cuba”, en: TulCHIN, Joseph S., Serbin, Andrés y Hernández, Rafael (eds.), Cuba and the Caribbean: Regional Trends in the Post-Cold War Era, Washington DC: Woodrow Wilson Center, pp. 207-243.

Gratius, Susanne. (1996), "Cuba and the European Union: A Fragile Relationship", Transitions, Vol. 37, ${ }^{\circ}$ 2, Bruxelles, pp. 39-51.
Hoffmann, Bert. (1997), "Helms-Burton und kein Ende? Auswirkungen und Perspektiven für Kuba, die USA und Europa", Lateinamerika: Analysen, Daten, Dokumentation, $\mathrm{n}^{\circ} 3$, Hamburgo, pp. 35-50.

INSTITUTO DE RELACIONES EUROPEO-LATINOAMERICANAS (IRELA). (1998), "El mundo se abre a Cuba: avances hacia su plena inserción internacional”, Briefing, $\mathrm{n}^{\circ} 3$, Madrid.

INSTITUTO DE RELACIONES EUROPEO-LATINOAMERICANAS (IRELA). (1997), "Cuba después del V Congreso del PCC”, Briefing, $\mathrm{n}^{\circ} 8$, Madrid.

INSTITUTO DE RELACIONES EUROPEO-LATINOAMERICANAS (IRELA). (1996), "La Posición Común de la UE sobre Cuba: debate interno, reacciones y repercusiones", Briefing, $\mathrm{N}^{\circ}$ 8, Madrid.

INSTITUTO DE RELACIONES EUROPEO-LATINOAMERICANAS (IRELA). (1996), "La Unión Europea y Cuba: las dificultades del diálogo", Briefing, $\mathrm{N}^{\circ} 5$, Madrid.

KINKA, Gerke. (1997), "The Transatlantic Rift over Cuba: The Damage is Done", The International Spectator, Vol. 32, n 2, Roma, pp. 27-52.

LeOGRANDE, William M. (1998), "From Havana to Miami: U.S. Policy as a Two-level Game", Journal of Interamerican Studies and World Affairs, Vol. 40, $\mathrm{N}^{\circ} 1$, Coral Gables/Florida, pp. 67-84.

Pelayo, Antonio. (1998), "El Papa en Cuba", Política Exterior, Vol. 12, n 62, Madrid, pp. 95- 103.

Pereira, Eduardo. (1996), "Cuba y la Unión Europea: los factores del estancamiento", Revista de Estudios Europeos, Vol 10, n 40, La Habana, pp. 78-116.

Robaina, Roberto. (1997), "La realidad cubana ante la Unión Europea”, Política Exterior, Vol. 11, n ${ }^{\circ} 57$, Madrid, pp. 87-93.

SAHAGÚN,'Felipe. (1996), "Cuba: un asunto interno español”, Meridiano CERI, $\mathrm{N}^{\circ} 10$, Madrid, pp. 4-9.

THOMAs, Isabella. (1996), "La Habana: las implicaciones de Helms-Burton", Política Exterior, Vol. 53, n 10, Madrid, pp. 91-100.

\section{RESUMEN}

En el artículo se analizan las relaciones entre Cuba y Europa en los últimos diez años. Estas se han caracterizado por la recuperación de las raíces europeas en Cuba en el marco del creciente papel de la Iglesia Católica en la isla y de la reconciliación con Europa.

Palabras claves: cooperación, relaciones internacionales, intercambio económico, diplomacia.

\section{ABSTRACT}

This article analyzes the relationships between Cuba and Europe over the last ten years. These relationships have been characterized by a renewed emphasis on the European roots of Cuba, the increasing role of the Catholic church in the island, and reconciation with Europe.

Key words: cooperation, international relations, economic exchanges, diplomacy. 